\title{
Erratum: An intrinsic mechanism controls reactivation of neural stem cells by spindle matrix proteins
}

Song $\mathrm{Li}^{1}$, Chwee Tat Koe ${ }^{1}$, Su Ting Tay ${ }^{2}$, Angie Lay Keng Tan ${ }^{2}$, Shenli Zhang ${ }^{2}$, Yingjie Zhang ${ }^{1,3}$, Patrick Tan ${ }^{2,4,5,6}$, Wing-Kin Sung ${ }^{6,7} \&$ Hongyan Wang ${ }^{1,3,8}$

Nature Communications 8:122 doi: 10.1038/s41467-017-00172-9; Article published online: 25 Jul 2017

The original version of this Article contained errors in the Abstract. 'Chro also prevents NSCs from ire-entering quiescence at later stages. NSC-specific in vivo profiling has dentified many downstream targets of Chro, including a temporal transcription factor Grainy head (Grh) and a neural stem cell quiescence-inducing factor Prospero (Pros)' now reads 'Chro also prevents NSCs from re-entering quiescence at later stages. NSC-specific in vivo profiling has identified many downstream targets of Chro, including a temporal transcription factor Grainy head (Grh) and a neural stem cell quiescence-inducing factor Prospero (Pros).' These errors have now been corrected in both the PDF and HTML versions of this Article.

Published online: 31 October 2017

\footnotetext{
(c) (i)

Open Access This article is licensed under a Creative Commons Attribution 4.0 International License, which permits use, sharing, adaptation, distribution and reproduction in any medium or format, as long as you give appropriate credit to the original author(s) and the source, provide a link to the Creative Commons license, and indicate if changes were made. The images or other third party material in this article are included in the article's Creative Commons license, unless indicated otherwise in a credit line to the material. If material is not included in the article's Creative Commons license and your intended use is not permitted by statutory regulation or exceeds the permitted use, you will need to obtain permission directly from the copyright holder. To view a copy of this license, visit http://creativecommons.org/licenses/by/4.0/.
}

(C) The Author(s) 2017

\footnotetext{
${ }^{1}$ Neuroscience and Behavioural Disorders Program, Duke-NUS Medical School, 8 College Road, Singapore 169857, Singapore. ${ }^{2}$ Cancer and Stem Cell Biology Program, Duke-NUS Medical School, 8 College Road, Singapore 169857, Singapore. ${ }^{3}$ NUS Graduate School for Integrative Sciences and Engineering, National University of Singapore, 28 Medical Drive, Singapore 117456, Singapore. ${ }^{4}$ Cellular and Molecular Research, National Cancer Centre, Singapore 169610, Singapore. ${ }^{5}$ Cancer Science Institute of Singapore, National University of Singapore, Singapore 119074, Singapore. ${ }^{6}$ Genome Institute of Singapore, 60 Biopolis Street, Genome 02-01, Singapore 138672, Singapore. ${ }^{7}$ Department of Computer Science, National University of Singapore, Singapore 117417 , Singapore. ${ }^{8}$ Department of Physiology, Yong Loo Lin School of Medicine, National University of Singapore, Singapore 117597, Singapore. Correspondence and requests for materials should be addressed to H.W. (email: hongyan.wang@duke-nus.edu.sg)
} 